\title{
The effectiveness of mindfulness-based training on anxiety in pregnant women with gestational diabetes
}

\author{
FATEMEH HAMIDI 1, A, B, F, MOJGAN JAVADNOORI 1, A, D, F, G, SEYED MEHDI HOSSEINIFARD ${ }^{2, \text { D, }}$ \\ ORCID ID: 0000-0003-0317-6477 ORCID ID: 0000-0001-7645-3629 ORCID ID: 0000-0003-1850-3370 \\ ROYA NIKBAKHT', c \\ ORCID ID: 0000-0002-9684-8529 \\ ${ }^{1}$ Reproductive Health Promotion Research Center, Department of Midwifery, Faculty of Nursing and Midwifery, \\ Ahvaz Jundishapur University of Medical Sciences, Ahvaz, Iran \\ ${ }^{2}$ Department of Psychiatry, Faculty of Medicine, Kerman University of Medical Sciences, Kerman, Iran \\ ${ }^{3}$ Department of Biostatistics, Faculty of Health, Mazandaran University of Medical Sciences, Sari, Iran
}

A - Study Design, B - Data Collection, C - Statistical Analysis, D - Data Interpretation, E - Manuscript Preparation, F - Literature Search, G - Funds Collection

Summary Background. Anxiety is more common during pregnancy than in any other periods. Thus, medical problems such as diabetes can increase the anxiety of pregnant women.

Objectives. The main objective of this study was to investigate the effectiveness of mindfulness-based training on anxiety in pregnant women with gestational diabetes.

Materials and methods. This study was a randomized controlled trial study with a pre-test, post-test and control group. Among 24-28 week pregnant women with diabetes who referred to health centers in Kerman, 88 women were selected. Participants were randomly allocated into intervention and control groups. Mindfulness-based training was used for the intervention group over 8 weeks, and situational and trait anxiety was measured through a Spielberg anxiety questionnaire. The collected data was analyzed using SPSS version 22 software.

Results. There was no significant difference between the mean scores of situational and trait anxiety before intervention in both the intervention and control groups $(p=0.159, p=0.21)$. However, mean situational and trait anxiety decreased in the intervention group and increased in the control group after intervention/treatment. There was significant increase over time. The difference between the two groups was also significant during the intervention and post-intervention periods ( $p$-value $<0.0001$ ).

Conclusions. Mindfulness-based counseling conducted by a midwife decreased the anxiety of pregnant women with gestational diabetes.

Key words: mindfulness, anxiety, gestational diabetes.

Hamidi F, Javadnoori M, Hosseinifard SM, Nikbakht R. The effectiveness of mindfulness-based training on anxiety in pregnant women with gestational diabetes. Fam Med Prim Care Rev 2020; 22(4): 279-283, doi: https://doi.org/10.5114/fmpcr.2020.100430.

\section{Background}

Anxiety is a common mental health problem, which is more common among women than men, especially during pregnancy more than other periods [1]. Anxiety is not constant during pregnancy, so it increases during the first and third trimester, decreases during the second trimester and becomes maximum at childbirth [2]. The prevalence of anxiety in pregnancy is about $18 \%$ [3]. Studies show that anxiety during pregnancy can directly affect the growth pattern of the fetus and duration of pregnancy [4]. It leads to side effects, such as preterm labor and low birth weight [5]. Anxiety also causes the secretion of stress hormones (adrenal steroids and corticotrophin releasing hormones), which can influence fetal brain development during weeks $12-22$ [6]. $15 \%$ of anxiety problems and cognitive delay in children are due to a mother's anxiety during pregnancy [7, 8]. Some of the causes of anxiety disorders in pregnant women include early maternal age, primiparity, hereditary anxiety, physical disease [9], history of preterm labor and high risk of fetal anomalies [10].

A common medical complication during pregnancy is gestational diabetes, defined as carbohydrate intolerance which is diagnosed and commences during pregnancy [10]. The prevalence of gestational diabetes varies from $1 \%$ to $14 \%$ in different parts of the world [11]. Its prevalence has been reported as being from $1.3 \%$ to $8.9 \%$ in Iran [12]. Fetal complications of gestational diabetes include fetal macrosomia, injuries during childbirth, hypoglycemia, hypocalcemia, hyperbilirubinemia and respiratory distress syndrome. Maternal complications include preeclampsia, preterm labor, hydramnios, cesarean delivery and type 2 diabetes in the future [13].

Pregnant women with diabetes need special care, because it has a great influence on their physical and mental health and increases their anxiety [14]. The prevalence of anxiety among diabetic people is $20 \%$ higher than non-diabetics [15]. Non-pharmacological interventions, such as cognitive-behavioral therapy (CBT) [16] and spiritual trainings [17], have been used to decrease anxiety during pregnancy. Recently, mindfulness-based interventions were developed and used for managing psychological problems during pregnancy [18]. Mindfulness is defined as consciousness and attention to what is happening at the present. It is considered as one of the cognitive-behavioral therapies of the third wave, which is a form of meditation [19]. Mindfulness-based interventions include Mindfulness-Based Stress Reduction (MBSR) and Mindfulness-Based Cognitive Therapy (MBCT) [20].

In previous studies, the effect of mindfulness-based interventions on reducing anxiety has been studied in different populations, including non-diabetic pregnant women and non-pregnant diabetic women [18, 21, 22]. Many studies have also 
been performed to investigate the effect of mindfulness training on self-efficacy and fear of childbirth in pregnant women [23]. A recent study on women aged 20-40 years with type 2 diabetes showed that a mindfulness-based stress reduction program was effective on decreasing anxiety, stress and $\mathrm{HbA}_{1 c^{\prime}}$ as well as increasing self-esteem [21]. Another study showed that the MBSR method is effective for diabetic people who suffer from emotional problems, anxiety and depression and can improve their health [24]. However, the effectiveness of this method on diabetic pregnant women has not been studied.

\section{Objectives}

To assess the effectiveness of mindfulness-based training on anxiety in pregnant women with gestational diabetes.

\section{Material and methods}

\section{Study design}

This was a randomized controlled trial study.

\section{Participants}

In the present study, pregnant women aged between 18-45 years, a gestational of age 24-28 weeks, with gestational diabetes, having the ability to read and write and having a situational anxiety score of 20-53 and a trait anxiety score of 20-56 were included. Exclusion criteria included a history of receiving mindfulness training, having pre-pregnancy diabetes and exposure to major stress due to unforeseen incidents (grief, divorce). The sample size was determined at 88 participants using G*Power software and was based on a similar article [18].

\section{Sampling method}

All pregnant women who were referred to health centers in Kerman were permitted to participate in the study after gaining their written consent and having received an explanation of the research objectives. Sampling was performed using the simple random sampling method. Participants were randomly allocated into intervention and control groups using a random number table.

The first researcher identified those pregnant women who were diagnosed with gestational diabetes in the health centers after reviewing their medical records and contacted them to asked if they were willing to participate in the study. They were later invited to an initial interview and to complete the questionnaire. Data was collected by a demographic questionnaire, an obstetric questionnaire and the Spielberg situational and trait anxiety inventory (STAI).

The STAI includes 40 questions scored on the Likert scale from "very low" to "very high", in which 20 questions are related to a sub-scale of situational anxiety (the emotion that person has), and the other 20 questions are related to a sub-scale of trait anxiety (underlying anxiety of a person and their willingness to be anxious). To determine the situational anxiety, scores of $20-30,31-42,43-53$ and $\geq 54$ show the lowest, mild, moderate and severe levels of anxiety, respectively. To determine trait anxiety, scores of 20-34, 35-45, 46-56 and $\geq 57$ show the lowest, mild, moderate and severe levels of anxiety, respectively. The first, second and third evaluations were performed before, immediately after and one month after intervention by STAI in both the intervention and control groups. The questionnaires were completed by participants in the presence of a researcher after explaining how to complete the questionnaires.

The intervention group was treated with mindfulness-based training over 8 sessions. The sessions were held for 120 minutes weekly by the first researcher, a graduate midwife studying MS in counseling in midwifery. During each session, the activities of the previous session were reviewed, and the consultation and concepts related to the meeting were then discussed, and the practical exercises of the session were performed at the end of the session. The control group only received routine pregnancy care and was not aware of the sessions held for the intervention group. At the end of the study, a book related to mindfulness and a training $C D$ of the counseling sessions were presented to all the participants.

The general structure of training sessions for MBSR is presented in Table 1. Data was analyzed using version 22 of SPSS software.

\section{Ethical consideration}

The protocol of this study was approved by the Ethics Committee of Ahvaz Jundishapur University of Medical Sciences (Ref No: 1088.1396IR.AJUMS.REC) and is registered with the Iranian Clinical Trials Centers (Ref No: IRCT20180627040261N1).

\section{Table 1. Structure of training sessions of MBSR}

First session: introducing participants, a brief description of 8 sessions, providing introduction on gestational diabetes, introducing a pilot automatic system, practice of eating a raisin and its feedback

Second session: awareness and presence at the moment, tackling barriers, sitting practice with awareness of breathing

Third session: attention, 3-minute respiratory interruption training

Forth session: admission, body scan practice

Fifth session: stress, involving in stressful reactions, response instead of reaction, sitting mediation associated with focus on breathing, body thoughts and sounds

Sixth session: thoughts are not truth, mindfulness practice when moving

Seventh session: self-care, sitting mediation, selecting each method that you want

Eighth session: end session and conclusion

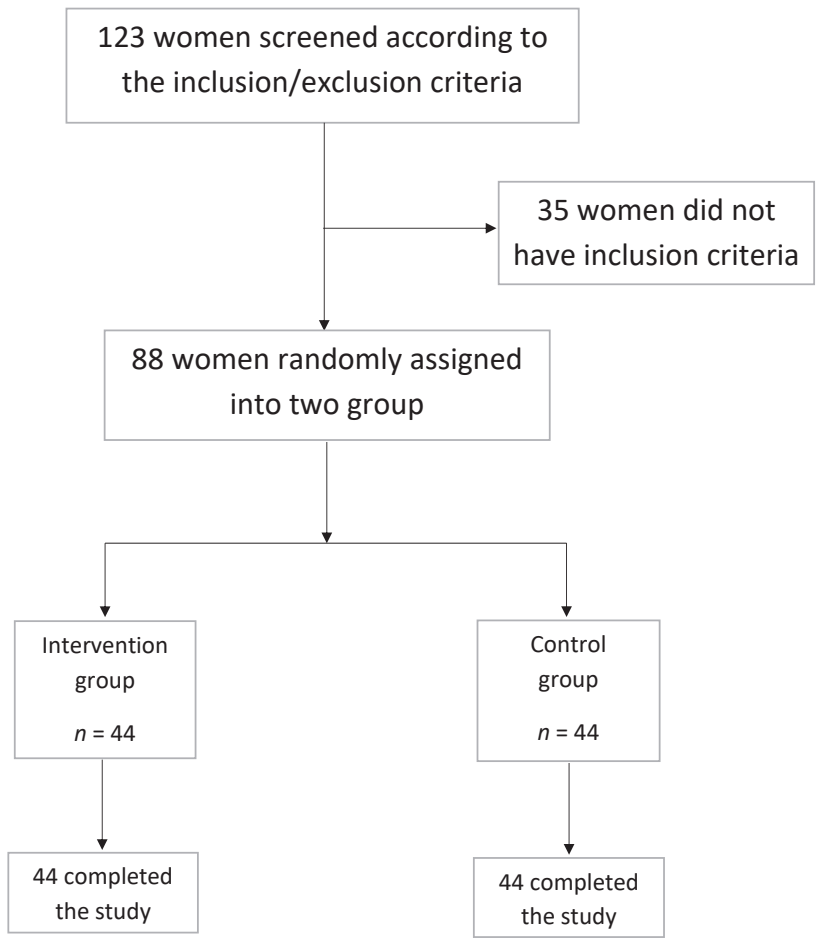

Figure 1. Flow diagram of the recruitment and retention of participants in the study 


\section{Results}

\begin{tabular}{|l|l|l|l|l|}
\hline \multicolumn{2}{|l|}{$\begin{array}{l}\text { Table 2. Demographic features of participants by groups } \\
\text { Group }\end{array}$} & $\begin{array}{l}\text { Control } \\
(n=44)\end{array}$ & $\begin{array}{l}\text { Intervention } \\
(n=44)\end{array}$ & $p$ \\
\hline Variable & Housewife & $24(54.5)$ & $25(56.8)$ & 0.830 \\
& Employed & $20(45.5)$ & $19(43.2)$ & \\
\hline Education* & Diploma and lower & $13(27.5)$ & $10(20.5)$ & 0.460 \\
& Associated degree & $6(15)$ & $11(25.6)$ & \\
\hline Parity* & Bachelor and higher & $25(57.5)$ & $23(53.8)$ & 0.580 \\
& 1 & $10(22.7)$ & $9(20.5)$ & \\
& 2 & $23(52.3)$ & $18(40.9)$ & $12(27.3)$ \\
\hline Age** & 3 & $8(18.2)$ & $5(11.4)$ & \\
\hline Gestational age** & 4 and more & $3(6.8)$ & $29.5 \pm 5.22$ & 0.931 \\
\hline
\end{tabular}

*Chi-square test was used, $* *$ independent-samples $t$-test was used.

\begin{tabular}{|l|l|l|l|l|}
\hline Table 3. The mean scores of situational and trait anxiety at the three time points \\
\hline Variable & Measure time & $\begin{array}{l}\text { Intervention group } \\
\text { (mean } \pm \text { SD) }\end{array}$ & $\begin{array}{l}\text { Control group } \\
\text { (mean } \pm \text { SD) }\end{array}$ & $p$ \\
\hline Situational anxiety & Before intervention & $47.09 \pm 5.40$ & $45.95 \pm 2.53$ & 0.210 \\
& Immediately after intervention & $33.90 \pm 2.86$ & $46.14 \pm 2.86$ & $<0.000$ \\
& One month after intervention & $33.36 \pm 2.78$ & $45.84 \pm 2.56$ & $<0.000$ \\
\hline Trait anxiety & Before intervention & $47.11 \pm 3.16$ & $46.25 \pm 2.50$ & 0.159 \\
& Immediately after intervention & $33.97 \pm 2.69$ & $45.35 \pm 2.38$ & $<0.000$ \\
& One month after intervention & $33.14 \pm 2.76$ & $45.23 \pm 2.57$ & $<0.000$ \\
\hline
\end{tabular}

* Repeated measures.

The Kolmogorov-Smirnov test was used to assess normality. Both situational and trait anxiety were normal ( $p>0.05$ ). Data was analyzed based on repeated measurements and two independent samples $t$-test and paired $t$-test. Two independent samples $t$-test and chi-2 test were also used in the demographic section. To determine the significance level of the tests, the alpha was considered as 0.05 .

Table 2 shows the demographic features of women who participated in the study. Two groups did not have any significant differences regarding demographic variables $(p>0.05)$.

Table 3 shows the mean scores of situational and trait anxiety at the three time points in the intervention and control groups. There was no significant difference between the mean of situational and trait anxiety and the control group before intervention ( $p=0.21, p=0.15$ ). However, immediately after intervention $(p<0.0001)$ and one month after intervention $(p<$ 0.0001 ), a significant difference between the intervention group and control group was found.

\section{Discussion}

The aim of this study was to assess the effectiveness of mindfulness training on anxiety among pregnant women with gestational diabetes. The results showed that mindfulness-based counseling provided by a midwife was effective in decreasing situational and trait anxiety in pregnant women with gestational diabetes.

In other studies, cognitive-based training provided by a midwife has been effective in decreasing the fear of delivery and increasing natural childbirth [25]. A cost-effectiveness analysis of cognitive trainings for pregnant women showed that these trainings are effective in decreasing the need for a cesarean section due to decreasing the fear of delivery [26].

In previous studies, the effect of mindfulness on anxiety or other mental health problems among non-diabetic and non-pregnant women [27], the anxiety of diabetic women [22, 24] and the anxiety of pregnant women [18], as well as the effect of similar interventions on anxiety in pregnant women with diabetes [17], has been showed. For example, in a study conducted by Rod, mindfulness-based exercises decreased anxiety and symptoms of depression in patients who suffered from chronic pain [27]. Mindfulness-based intervention decreased anxiety, stress and depression levels and also increased self-confidence and decreased $\mathrm{HbA}_{1 \mathrm{c}}$ and blood glucose [21, 22, 24]. A mindfulness-based training program has also been useful in reducing the anxiety of non-diabetic pregnant women [18].

Training of mindfulness-based skills, both statistically and clinically, significantly decreased the symptoms of vulnerable people and anxiety [28]. It has also been shown that mindfulness-based trainings can increase the self-efficacy of delivery and decrease depression after delivery [29].

It can be said that due to the problems and limitations that gestational diabetes causes for pregnant women, their anxiety will be doubled.

In this situation, these women are strongly prepared to learn new ways for reducing their anxiety. Common approaches used to reduce anxiety and depression and increase quality of life are spiritual training [30] and cognitive-behavioral training [16]. Group spiritual therapy decreased anxiety and increased quality of life in pregnant women with diabetes [30]. It is suggested that midwife-led psychological training approaches should be used to improve the mental health of pregnant women. Thus, training of interdisciplinary skills such as psycho-educational approaches for midwives can be cost-effective.

The current research is the first study on pregnant women with gestational diabetes which investigates the effect of mindfulness-based training on anxiety. In future studies, the effect of mindfulness-based training can be compared with other psychological approaches to decrease the anxiety of pregnant women with gestational diabetes. Additionally, it is suggested that future studies examine the impact of involving a family member in the education process. 


\section{Limitations of the study}

A number of important limitations need to be considered: first, the uncertainty about the accuracy of information provided by the participants, and the second, self-reporting of the variables examined.

\section{Conclusions}

Mindfulness-based counseling is an effective way to decrease the anxiety of pregnant women with gestational diabetes. Therefore, mindfulness-based counseling can be used to improve the mental health of pregnant women with gestational diabetes.

Acknowledgements. This article is an excerpt from the MSc thesis in midwifery counseling, at Ahvaz Jundishapur University of Medical Sciences, owned by F. Hamidi. The authors express their gratitude to the authorities of health centers in Kerman and all the pregnant women who helped us in this research.

Source of funding: This work was funded from the authors' own resources.

Conflicts of interest: The authors declare no conflicts of interest.

\section{References}

1. Simpson KR, Creehan PA. Perinatal nursing. 4th ed. 2014. Philadelphia: Lippincott Williams and Wilkins; 2014: 302-305.

2. Figueiredo B, Conde A. Anxiety and depression symptoms in women and men from early pregnancy to 3-months postpartum: parity differences and effects. J Affect Disord 2011; 132(1-2): 146-157.

3. George A, Luz RF, De Tychey C, et al. Anxiety symptoms and coping strategies in the perinatal period. BMC Pregnancy Childbirth 2013; 13: 233.

4. Fink NS, Urech C, Cavelti M, et al. Relaxation during pregnancy: what are the benefits for mother, fetus, and the newborn? A systematic review of the literature. J Perinat Neonatal Nurs 2012; 26(4): 296-306.

5. Field T, Hernandez-Reif M, Figueiredo B, et al. Comorbid depression and anxiety effects on pregnancy and neonatal outcome. Infant Behav Dev 2010; 33(1): 23-29.

6. Weinstock M. The long-term behavioural consequences of prenatal stress. Neurosci Biobehav Rev 2008; 32(6): $1073-1086$.

7. Okour AM, Badarneh R. Spousal violence against pregnant women from a Bedouin Community in Jordan. J Womens Health (Larchmt) 2011; 20(12): 1853-1859.

8. Brownridge DA, Taillieu TL, Tyler KA, et al. Pregnancy and intimate partner violence: risk factors, severity, and health effects. Violence Against Women 2011; 17(7): 858-881.

9. Adewuya A, Ola B, Aloba O, et al. Anxiety disorders among Nigerian women in late pregnancy: a controlled study. Arch Womens Ment Health 2006; 9(6): 325-328.

10. Cunningham G, Leveno K, Bloom S, et al. Williams obstetrics. 24th ed. New York: McGraw-Hill; 2014

11. American Diabetes Association. Classification and diagnosis of diabetes mellitus. Diabetes Care 2010; 33(Suppl. 1): S62-S69.

12. Mirfaizi M, Azarian AA, Mirheydari M. Evaluate the frequency and risk factors for gestational diabetes in pregnancy women living in Karaj. Diabet and Lipid 2010; 4(9): 376-382 (full text in Persian).

13. Sun $\mathrm{Y}$, Zhao $\mathrm{H}$. The effectiveness of lifestyle intervention in early pregnancy to prevent gestational diabetes mellitus in Chinese overweight and obese woman: a quasi-experimental study. Appl Nurs Res 2016; 30(5): 125-130.

14. Murphy NM, McCarthy FP, Khashan AS, et al. Compliance with national institute of health and care excellence risk-based screening for gestational diabetes mellitus in nulliparous women. Eur J Obstet Gynecol Reprod Biol 2016; 199(1): 60-65.

15. Li C, Barker L, Ford ES, et al. Diabetes and anxiety in US adults: findings from the 2006 Behavioral Risk Factor Surveillance System. Diabet Med 2008; 25: 871-881.

16. Choate LH, Gintner GG. Prenatal depression: best practice guidelines for diagnosis and treatment. J Couns Dev 2011; 89(3): 373-381.

17. Beigi A, Habibi S, Rezaei $\mathrm{H}$, et al. Effect of spiritual training on decrease anxiety and increased quality of life of women with gestational diabetes in the assessment of nursing and modern care. J Diabetes Nurs 2016; 4(3): 19-29 (full text in Persian).

18. Yazdanimehr R, Omidi A, Sadat Z, et al. The effect of mindfulness-integrated cognitive behavior therapy on depression and anxiety among pregnant women: a randomized clinical trial. J Caring Sci 2016; 5(3): 195-203.

19. Robins JLW, Kiken L, Holt M, et al. Mindfulness: an effective coaching tool for improving physical and mental health. J Am Assoc Nurse Pract 2014; 26(9): 511-518.

20. Bear RA. Mindfulness training as a clinical intervention: a conceptual and empirical review. Clin Psychol Sci Pract 2003; 10(2): 125-143.

21. Vala M, Razmandeh R, Rambod K, et al. Mindfulness-based stress reduction group training on depression, anxiety, stress, self-confidence and hemoglobin A1c in young women with type 2 diabetes. IJEM 2015; 17(5): 382-390 (full text in Persian).

22. Pearson S, Wills K, Woods $\mathrm{M}$, et al. Effects of mindfulness on psychological distress and $\mathrm{HbA}_{1 \mathrm{c}}$ in people with diabetes. Mindfulness 2018; 9(5): 1615-1625.

23. Byrne J, Hauck Y, Fisher C, et al. Effectiveness of a mindfulness-based childbirth education pilot study on maternal self-efficacy and fear of childbirth. J Midwifery Womens Health 2014; 59(2): 192-197.

24. Son J van, Nyklicek I, Pop VJ, et al. Mindfulness-based cognitive therapy for people with diabetes and emotional problems. J Psychosom Res 2014; 77(1): 81-85.

25. Fenwick J, Toohill J, Gamble J, et al. Effects of a midwife psycho-education intervention to reduce childbirth fear on women's birth outcomes and postpartum psychological wellbeing. BMC Pregnancy Childbirth 2015; 15: 284.

26. Toohill J, Callander E, Gamble J, et al. A cost effectiveness analysis of midwife psycho-education for fearful pregnant women - a health system perspective for the antenatal period. BMC Pregnancy Childbirth 2017; 17(1): 217.

27. Rod K. Observing the effects of mindfulness-based meditation on anxiety and depression in chronic pain patients. Psychiatr Danub 2015; 5(4): 143-147.

28. Tanay $G$, Lotan $G$, Bernstein A. Salutary proximal processes and distal mood and anxiety vulnerability outcomes of mindfulness training: a pilot preventive intervention. Behav Ther 2012; 43(3): 492-505.

29. Duncan LG, Cohn MA, Chao MT, et al. Benefits of preparing for childbirth with mindfulness training: a randomized controlled trial with active comparison. BMC Pregnancy Childbirth 2017; 17(1): 140.

30. Niaz Azari M, Abdollahi M, Zabihi Hesari NKh, et al. Effect of spiritual group therapy on anxiety and quality of life among gestational diabetic females. Religion and Health 2017; 5(1): 11-20 (full text in Persian). 
Tables: 3

Figures: 1

References: 30

Received: 24.09 .2019

Reviewed: 18.10 .2019

Accepted: 14.01 .2020

Address for correspondence:

Mojgan Javadnoori, PhD, Assoc. Prof.

Department of Midwifery

Faculty of Nursing and Midwifery

Ahvaz Jundishapur University of Medical Sciences

Golestan BLV

Ahvaz

Iran

Tel.: +98 6133738395, 6133738333

E-mail:mojganjavadnoori@gmail.com, javadnoori-m@ajums.ac.ir 